\title{
Effects of Creep Failure Mechanisms on Thermo- mechanical Reliability of Solder Joints in Power Semiconductors
}

\author{
Vahid Samavatian, Hossein Iman-Eini, Senior Member, IEEE, Yvan Avenas and Majid Samavatian
}

\begin{abstract}
This paper deals with the effects of creep failure mechanism on thermo-mechanical reliability of power semiconductors. Regarding power semiconductors' working conditions, fatigue and creep failure mechanisms are the two most critical failure origins in power semiconductors. Here we propose an approach to show the role of creep event on the creep-fatigue failure mechanism of a power semiconductor. The results show that $34 \%$ difference in the lifetime prediction appears when the creep is considered in the estimations. This indicates that the extra effect of creep on fatigue evolution of power systems can markedly decrease the lifetime which is ignored in many cases. Moreover, a logarithmic trend for thermal resistance and on state voltage drop upon increase in number of thermo-mechanical cycles implies the accelerated aging of power semiconductor.
\end{abstract}

Index Terms - physics of failure, reliability assessment, creep, fatigue, Power semiconductor, thermo-mechanical reliability.

\section{INTRODUCTION}

$\mathrm{O}$ NE of the most vulnerable part in power converters is undoubtedly power semiconductor [1], [2]. Power devices play central roles in the performances of power converters. These devices are strictly exposed to internal and external stresses. Regarding their laminated structures, the most important stressor, they are exposed to, is electro thermomechanical stress [3]. Although, considerable studies have taken into account electro thermo-mechanical fatigue failure mechanisms [4], [5], another important failure mechanism, namely creep mechanism, has been neglected.

Many studies have been done to evaluate the effects of thermo-mechanical cycling on the reliability of solder joints in electronic packages. Amalu et al [6] investigated the thermomechanical response of solder joints in a crystalline silicon solar cell assembly using Garofalo-Arrhenius creep model. Their results indicate that the joint dimension plays a vital role in the thermo-mechanical reliability of solder joints. Talebanpour et al [7] investigated the influence of thermalmechanical history on the creep behavior of Sn-based solders. It was found that during power cycles ranging from 0.44 to 0.8 $\mathrm{T}_{\max }$, the thermal cycling reliability of power electronic packages was steeply declined. Le et al [8] indicated that process-induced voids acts as a key role in the creep-fatigue lifetime of solder joints of a power module. The voids are the potential sites for the concentration of stress and crack initiation

V. Samavatian is with the School of Electrical and Computer Engineering, College of Engineering, University of Tehran, Tehran, Iran and the Univ. Grenoble Alpes, CNRS, Grenoble INP (Institute of Engineering Univ. Grenoble Alpes), G2Elab, 38000 Grenoble, France (e-mail: vahidsamavatian@ut.ac.ir).

H. Iman-Eini is with the School of Electrical and Computer Engineering, College of Engineering, University of Tehran, Tehran, Iran (e-mail: imaneini@ut.ac.ir). in the solder joints. There are also some other works modeling and demonstrating the role of primary voids trapped in the solder material [9], [10]. Zhang et al [11] used finite element simulation and showed that the maximum stress concentrated location established a relationship with heights of solder joints. Chen et al [12] proposed a model to evaluate the coupling damage effects of low cycle fatigue and creep events under thermal cycling of an electronic device. Their case study on a lead free solder joint validated the damage model. CoffinManson method was used to evaluate the solder joints in a package-on-package structure [13]. It was reported that the maximum inelastic hysteresis energy accumulates on the solder joints in the bottom fine-pitch ball grid array structure. The thermal-fatigue crack also initiates in the two symmetrical corners of solder balls in fine-pitch ball grid array structure. Zhang et al [14] applied simulation along with Taguchi method to study the thermo-mechanical reliability of solder joints in a FGBGA device subjected to a thermal cyclic loading. They revealed that the solder material is the most significant factor among the control factors in the device. Baber and Guven [15] proposed a peridynamic approach to predict fatigue lifetime of solder joints. This approach expresses that the material degradation through energy dissipative mechanisms plays a key role in crack initiation and propagation and the cracks follow paths similar to cracks produced under quasi-static cycling. Metais et al [16] proposed a viscoplastic-fatigue-creep damage model based on a non-linear mechanical behavior of solder at the beginning of deformation as well as during continuous cyclic aging. Material modeling concentrated on the interpretation of the complicated interaction between fatigue and creep and viscoplastic processes. Their results had a good agreement with the experimental works.

Regarding the conditions under which power devices are working, creep as well as fatigue failure mechanisms both may be activated. Consideration of creep effects along with fatigue failure mechanism is still under debate in the power electronics field. The objective of this paper is to address the raised question that how the interaction of fatigue and creep failure mechanisms influences the damage evolution of solder joints in power devices in real conditions. Therefore, this paper is prepared to carry out the real mission profile based coupled creep-fatigue useful lifetime estimation. Using FEM simulation, basic data associated to the steady state creep strain rate is provided. The data is utilized to evaluate damage

Y. Avenas is with the Univ. Grenoble Alpes, CNRS, Grenoble INP (Institute of Engineering Univ. Grenoble Alpes), G2Elab, 38000 Grenoble, France (e-mail: yvan.avenas@g2elab.grenoble-inp.fr).

M. Samavatian is with the Department of Advanced Materials and Renewable Energy, Iranian Research Organization for Science and Technology (IROST), Tehran, Iran (email: m.samavatian@srbiau.ac.ir) 
evolution with the coupled damage approach. Furthermore, experimental tests are used to deeply study the actual aspect of this failure mechanism in the solder joint. The remainder of this paper is organized as follows: Section II deals with the probable failure mechanisms in the power semiconductors. While section III deals with the proposed creep-fatigue reliability framework, experimental procedure and finite element (FE) simulation are respectively discussed in sections IV and V. Results and discussion are carried out in section VI.

\section{CRitical Failure MEChanismS}

\section{A. Electro-thermo-mechanical fatigue failure mechanism}

From a physical point of view, the repeated variations of stress may induce alternate plastic strains producing internal micro stresses responsible of microdecohesions by slip band arrests. The initiated micro cracks grow either inside the crystals or along the grains boundaries, depending on the materials and the loadings, up to coalescence corresponding to initiation of a mesocrack. Plastic strain and stress both participate in this phenomenon [17].

Power semiconductors are exposed to different thermal cycles owing to their power losses made in the chip junction. Electrical losses lead to heating up the bodies and consequently these temperature changes cause thermal strains. Regarding physical structure of power devices comprising various layers with different coefficients of thermal expansion (CTE) from $3.5 \times 10^{-6} / \mathrm{K}$ for silicon to $17 \times 10^{-6} / \mathrm{K}$ for copper and $22.3 \times 10^{-6} / \mathrm{K}$ for aluminum, a meaningful set of shear and normal stresses are induced in these layers [4]. These thermal stresses finally lead to the thermal strains in all bodies. Thereby, electro-thermomechanical fatigue has been occurred during the power semiconductor operations and may influence the health of power devices. The fatigue phenomenon leads to micro cracks production and growth as well as voids creation and coalescence which can affect the performance of any parts of packaging in a power device comprising bonding wires, aluminum metallization, die attach to the baseplate, etc.

\section{B. Solder joint creep-fatigue failure mechanism}

In general, the time-dependent strength of most materials deteriorates with the increase in the operating temperature. The creep and creep-fatigue failures are the events activated with the rise in temperature above the one-third of melting point of metals. The mentioned events are intensified upon passing of the time under external forces acting, when high temperature induces viscous effects to the materials. Creep-fatigue failures are the consequence of plastic strains occurring under constant temperature loading and temperature ramp up/down which materially solder joint does not differentiate between these two situations, but possible to be distinguished quantitatively in the equations. From a physical viewpoint, the evolution of creep damage includes the formation and growth of micro-voids, micro-crack formation at inter-granular sites and their coalescence in the crystals triple points. It is also suggested that the formation of inter-granular micro-cracks under fatigue cycles can develop among the grain boundaries and interact with the defects caused by the creep event. This interaction is nonlinear and the effects of the accumulated damage are associated with the materials properties, environmental conditions, system design and etc. [18], [19].

Regarding low melting temperature, the solder joint is undoubtedly the most fragile part in the power semiconductor, as a creep-fatigue failure mechanism point of view. In recent years, Sn-Ag-Cu (SAC) based solder materials with low melting point and superior mechanical properties have been proposed in the electronic industries. However, their reliability features, including fatigue resistance and creep behavior, play a major role in power electronic packages. In the meantime, it was found that solder joints were the most vulnerable parts for the damage initiation and the failure [20], [21]. In order to evaluate the reliability of solder joints under a thermomechanical loading, it is required to analyze the creep behavior of the solder and then the produced strain takes into account of fatigue evolution.

Recently, several studies have been published on the constitutive equation for creep strain analysis of SAC solders [22], [23]. Among them, Garofalo-Arrhenius creep model is one of the most applicative constitutive models for evaluation of SAC solder joints [23]. This model proposes a hyperbolic sine creep equation to model the creep event of the solder joints. The following equation demonstrates the steady state creep strain rate [24]:

$$
\dot{\varepsilon}_{c r}=C_{1}\left[\sinh \left(C_{2} \sigma\right)\right]^{C_{3}} \exp \left(-C_{4} / T\right)
$$

$\dot{\varepsilon}_{c r}$ is the creep strain rate and $C_{1}, C_{2}, C_{3}$ and $C_{4}$ are constant values for SAC solder [25]. The creep event is the primary damage mechanism for Sn-based solder joints under thermal cycling [24]. Hence, it is necessary to consider the creep strain in the life prediction model. $\sigma$ is the applied stresses induced by temperature swing $(\Delta T)$ and thereby they can replace.

\section{Lifetime model \\ C.1. Fatigue failure mechanism lifetime model}

On the contrary to passive thermal cycling test in which temperature swing is being induced by external homogeneous heating source, the device under test (DUT) is exposed to electrical loading in active thermal cycling test leading to faster temperature swing in the DUT junction. The heating up and cooling down rates generally take a few seconds. These steeply changes in the junction temperature can make sharp thermomechanical stresses in all bodies. However, in the passive temperature cycling, all bodies of component are exposed to the external temperature variations. It takes much higher time in comparison to active temperature cycles. There are numerous proposed lifetime estimation models for thermal fatigue failure mechanism in the active thermal cycling test [26]. Based on LESIT [27] experiment, the junction temperature swing $\left(\Delta T_{j}\right)$ and the mean junction temperature $\left(T_{\text {mean }}\right)$ are found to be the two most important factors in lifetime and damage evolution models. In addition to these two factors, however, Bayerer et al [28] have proposed a lifetime model considering on time of the active cycle $\left(t_{o n}\right)$ and current per wire bond $(I)$ for the specified and fixed power semiconductors. Since stationary creep phenomenon is also involved in this study, Coffin-MansonArrhenius lifetime model has been employed [27]. The model defined as follows: 


$$
N_{f}\left(T_{\text {mean }}, \Delta T_{j}\right)=A \times \Delta T_{j}^{\alpha} \times \exp \left(Q / R T_{m}\right)
$$

where $A, \alpha$ are both constant and device-dependent. $\Delta T_{j}$ expresses the junction temperature swing of devices in ${ }^{\circ} C . N_{f}$ is the number of cycle to failure based on the failure criteria definition. $R$ and $Q$ are the gas constant $\left(8.314 \mathrm{~J}^{\mathrm{M}} \mathrm{Mol}^{-1} \cdot \mathrm{K}^{-1}\right)$, internal energy and $T_{\text {mean }}$ is the mean junction temperature of devices in Kelvin.

\section{C.2. Creep lifetime model}

In most materials, a temperature increase leads to a decrease in the strength of material. In the creep mechanism the time and the temperature are both paramount of importance due to its physical mechanism. On the contrary to the fatigue damage process, namely load cycles, creep degradation is timedependent and highly impressed by the dwelling time period [10]. It is worth-mentioning that the pure creep strain is accumulated during the hot dwelling time, while the induced strain during the temperature ramping is mainly, not thoroughly, due to the sharp differences in the CTE of components and is associated to the fatigue mechanism [12]. For expressing lifetime model of the materials on the creep failure mechanism, Monkman-Grant (MG) model has been extensively used [29]:

$$
\dot{\varepsilon}_{c r} t_{c}^{\beta}=C_{M G}
$$

where $\dot{\varepsilon}_{c r}$ is the stable creep strain rate expressed by (1), $C_{M G}$ and $\beta$ are constant and material-dependent. It should be noted that the creep strain in (3) is related to the hot dwelling time.

It was previously mentioned and also revealed from (3) that the creep failure mechanism is time dependent which means that the longer time the material is exposed to the roughly constant temperature, the more degradation occurs. Based on Monkman-Grant model, the dwelling time $(\Delta t)$ is a key factor in calculating the creep useful lifetime.

\section{C.3. Creep-fatigue lifetime model interaction}

Previous works have only been limited to the fatigue by considering only the stress swings and the mean stresses and failed to purpose the dwelling times in which the material have been rested in the roughly constant temperature. Fig. 1 demonstrates a thermal stress as a function of time. As it is shown in the thermal stresses, there can be a lot of dwelling times in which the material is exposed to. Thus, it is thoroughly important to also consider the creep failure mechanism in lifetime estimation. Creep-fatigue coupled analysis is becoming important owing to solder working temperature range.

\section{Damage model}

\section{D.1. Fatigue failure mechanism damage model}

Several deterministic damage accumulation models have been proposed mainly fallen into two categories [30], [31]: linear and nonlinear damage cumulative models. Among these fatigue damage accumulation models, the linear damage accumulation theory, also known as Palmgren-Miner's rule [32], is commonly used in analyzing cumulative fatigue damage due to its relative simplicity, close approximation to reality, and widespread knowledge and utilization. The Miner's rule can be expressed as [33]:

$$
D_{F}=\sum_{i=1}^{n} N_{i}\left(T_{m}, \Delta T_{j}\right) / N_{f i}\left(T_{m}, \Delta T_{j}\right)
$$

where $D_{F}$ is the total linear accumulated damage, $N_{i}$ is the number of the $i^{\text {th }}$ particular cycle, $N_{F i}$ is the number of cycles to failure of the $i^{\text {th }}$ particular cycle and $\mathrm{n}$ is the number of distinct cycles which power semiconductors are subjected to.

However, linear damage cumulative models have some detriments such as absence of considering load history, load sequence effects and effects of load interaction. Under complex loading, either small cycles or large cycles are dependent on loading interaction, sequence, or memory effects. Nonlinear damage cumulative models have tried to overcome these detriments by proposing several methods such as damage theories based on the physical property degradation of materials, damage curve approaches, continuum damage mechanics approaches, damage theories based on energy, damage theories accounting for load interaction effects, damage theories based on thermodynamic entropy [33]. Although these methods have been proposed through recent years, they could not satisfy the users due to their complexity and also because of some disadvantages reported in [34]. That is why linear damage cumulative models also have taken many interests.

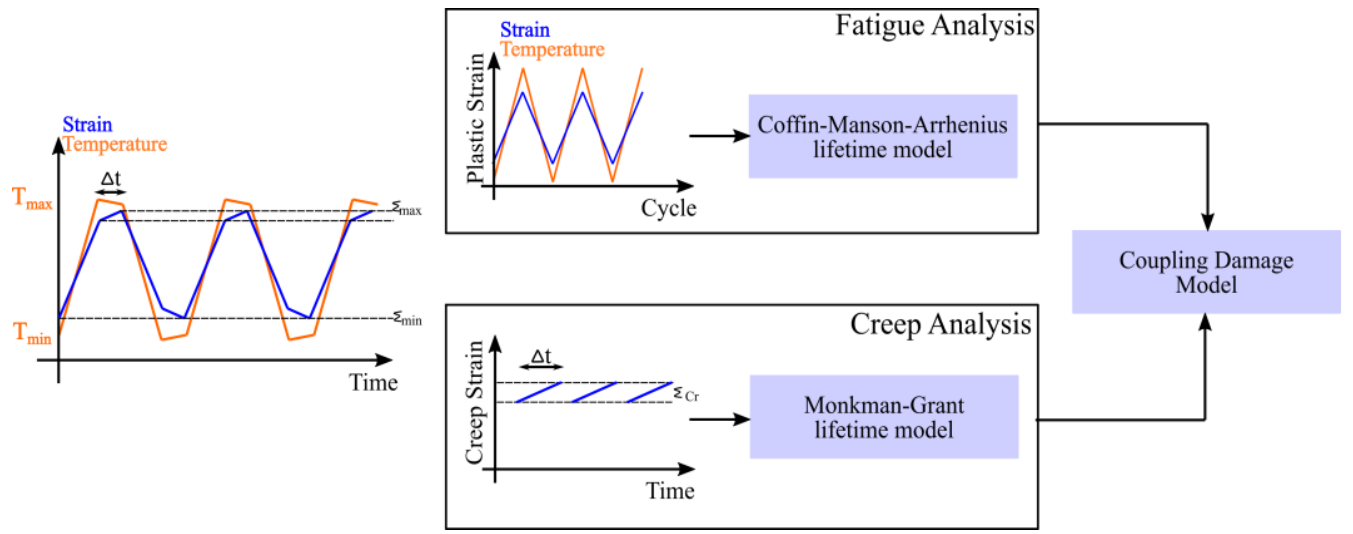

Fig. 1. Coupled creep-fatigue lifetime estimation model. Resulted strain cycles decompose into creep and fatigue events. 


\section{D.2. Creep damage model}

There are many damage models available for solder creep. They can be categorized into three groups: creep strain based, creep energy based, and damage accumulation based [25]. Damage accumulation model is based on the MG model. Thus, one can find time per unit creep damage as follows:

$$
d_{C}=1 / t_{c}=\left(\dot{\varepsilon} / C_{M G}\right)^{1 / \beta}
$$

Accumulated creep damage during the dwelling period under the same condition gives as

$$
D_{C}=\Delta t / t_{c}=\Delta t\left(\dot{\varepsilon} / C_{M G}\right)^{l / \beta}
$$

where $\Delta t$ is the dwelling time. Creep damage accumulation model has been widely used in several studies and can predict the useful lifetime with an acceptable precision [35].

\section{D.3. Coupled creep-fatigue damage model}

Although there are many fatigue-creep damage coupling models such as strain range partitioning, strain energy partitioning, frequency-modified strain-life equation, unified damage and mechanism-based model [36], [37], the global linear damage model [37] will be assumed and expressed as follows

$$
D=D_{F}+D_{C}
$$

where $D_{F}$ and $D_{C}$ are defined by (4) and (6) respectively.

\section{CREEP-FATIGUE Reliability FrameWORK}

In this section, the effects of creep failure mechanism consideration in the reliability assessment of power electronic semiconductors will be discussed. In this case, for the lifetime models of power devices both Coffin-Manson-Arrhenius (2) and Monkman-Grant (3) have been employed for fatigue and creep failure mechanisms, respectively. Global linear damage model (7) has been also used for obtaining accumulated damage in the power semiconductors.

The procedure of the proposed framework for useful lifetime estimation is shown in Fig. 2. Regarding this figure, the critical mission profile has to be sorted to be applicable to CoffinManson-Arrhenius and Monkman-Grant using a modified Rainflow algorithm [35]. Thereby, $\Delta T_{j}, T_{\text {mean }}, \Delta t$ and $T_{\max }$ would be classified through Rainflow algorithm and become ready to be applied to the lifetime models. Based on the Coffin-MansonArrhenius lifetime model, $\Delta T_{j}$ and $T_{\text {mean }}$ are the two key factors in number of cycles to failure assessment as expressed in (2). Therefore, these two parameters would be applied to the fatigue failure model. The other constant coefficients of this model, namely $A, \alpha$ and $Q$, were extracted from power cycling tests considering $20 \%$ increase in their critical parameters, namely on-state voltage and junction-case thermal resistance, as the failure criteria in individual test under a unique specified conditions (Section IV.B). On the other side based on the Monkman-Grant model, dwelling time $(\Delta t)$ and creep strain rate $\left(\dot{\varepsilon}_{c r}\right)$ are the most important parameters in the creep lifetime

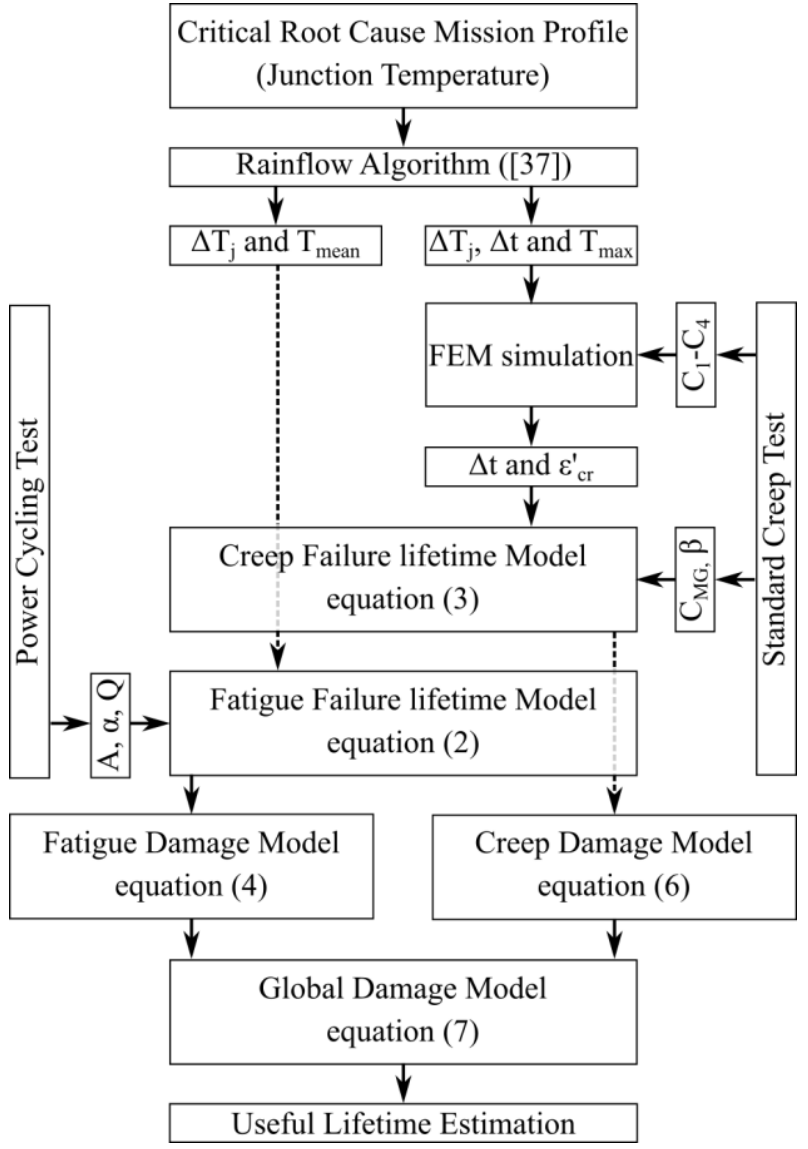

Fig. 2. Proposed useful lifetime assessment procedure.

estimation. Thus, a set of FEM simulations was performed in order to correlate $\Delta T_{j}, \Delta t$ and $T_{\max }$ (obtained from Rainflow algorithm) to $\Delta t$ and $\dot{\varepsilon}_{c r}$ using Garofalo-Arrehenius consecutive equation (1) for characterizing the creep strain rates which occur in the solder joint under different conditions (Section V). These processed data would be applied to Monkman-Grant lifetime model in order to calculate damage evolution regarding creep failure mechanism. Constant coefficients of GarofaloArrehenius consecutive equation $\left(C_{1}\right.$ to $\left.C_{4}\right)$ and MonkmanGrant lifetime model $\left(C_{M G}\right.$ and $\beta$ ) were extracted from standard creep tests (Section IV.A). Since, a Rainflow-sorted complex loading is considered and several loads with the distinct conditions are applied to the power device, cumulative damage models have to be utilized in order to determine the resulted damage evolution of each load. Thus, the outputs of lifetime models, namely creep and fatigue mechanisms, would be separately inserted to the cumulative damage models defined in (4) and (6). Finally, linear global damage model expressed in (7) would be employed for the useful lifetime estimation of the power semiconductor. Based on the empirical definition, the failure occurs when $\mathrm{D}=\mathrm{D}_{\mathrm{C}}+\mathrm{D}_{\mathrm{F}}=1$.

\section{EXPERIMENTAL PROCEDURE}

In this section, three implemented tests are described. A standard creep test was performed in order to characterize the creep behavior of SAC solder joint and extract the material constants for the constitutive equation describing creep steady state strain rate of material (see (1); $C_{1}, C_{2}, C_{3}$ and $C_{4}$ ). A power cycling test was performed in order to activate fatigue failure 


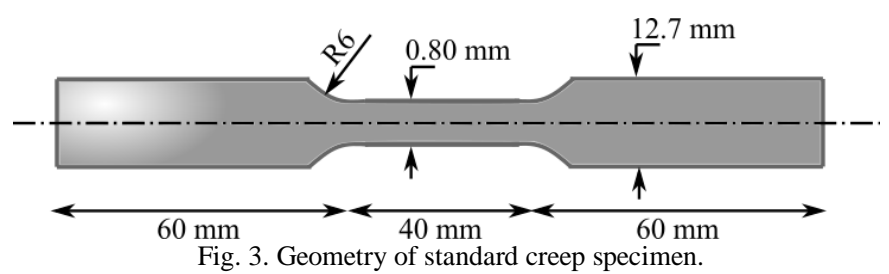

mechanism and obtain fatigue lifetime model parameters (see (2); $A, \alpha$ and $Q$ ). In addition, a standard thermal cycling test was also performed to demonstrate the damage evolution of solder joints under sever thermal loading. This damage evolution would be discussed in two aspects, namely microstructure and electrical aspects.

\section{A. Creep test}

Solder tensile specimen was designed based on the standard guidelines [38], [39]. The solder specimen $(\mathrm{Sn} 3.5 \mathrm{Ag} 0.5 \mathrm{Cu})$ is illustrated in Fig. 3. Regarding this figure, a uniform uniaxial stress in the declined radius gauge section was obtained. The dimensions are also illustrated in Fig. 3. Tensile tests at the constant strain rate test conditions can be used to characterize the creep steady strain rate data at high stress levels. Constant strain rate tensile tests were reported by [40]. Four temperatures including $-40^{\circ} \mathrm{C}, 25^{\circ} \mathrm{C}, 75^{\circ} \mathrm{C}$ and $125^{\circ} \mathrm{C}$ under three different strain rates, namely $5.6 \times 10^{-4}, 5.6 \times 10^{-3}$ and $5.6 \times 10^{-2} \mathrm{~s}^{-1}$, were performed. Regarding the results one can easily curve-fit the creep constant coefficients, i.e. $C_{1}, C_{2}, C_{3}$ and $C_{4}$.

\section{B. Power cycling test}

Several active power cycling tests were performed in order to activate and characterize the fatigue failure mechanism of several 600V-15A power IGBTs from Infineon Company, with the commercial product number of IKP15N60T fabricated based on the trench-gate field-stop technology. 15A constant current was injected through the IGBTs. Junction temperatures of devices were controlled adjusting on and off time of current injection. These tests were done for 8 different conditions, namely $\Delta T_{j}=\left\{70^{\circ} \mathrm{C}, 90^{\circ} \mathrm{C}, 110^{\circ} \mathrm{C}, 130^{\circ} \mathrm{C}\right.$; $\left.T_{\text {mean }}=95^{\circ} \mathrm{C}\right\}$ and $\Delta T_{j}=\left\{70^{\circ} \mathrm{C}, 90^{\circ} \mathrm{C}, 110^{\circ} \mathrm{C}, 130^{\circ} \mathrm{C}\right.$; $\left.T_{\text {mean }}=105^{\circ} \mathrm{C}\right\}$. The power devices were mounted on a fixed-temperature $\left(40^{\circ} \mathrm{C}\right)$ cold plate to ensure temperature stabilization in the resting (off) time. Failure criteria were considered as $20 \%$ increase either in onstate collector-emitter voltage or junction-case thermal resistance. The procedure of thermal resistance estimation is based on thermo sensitive electrical parameters (TSEP) and explained in [41] implemented by the authors. Details of procedures and data acquisitions of these set of experiments have been thoroughly explained in [42], [43] by the authors.

\section{Thermal cycling Test}

In this test, an automatic chamber was employed for performing accelerated thermal cycling test. This test was designed for activating creep failure mechanism in power semiconductors in order to demonstrate creep damage evolution in the solder joint.

Thermal cycling test was based on JESD22-A105C standard [44] and performed for several months and 2500 cycles (-40 to $170^{\circ} \mathrm{C}$ ) in a programmable chamber. Hot and cold dwelling times are $20 \mathrm{~min}$ and heating and cooling rates are $4{ }^{\circ} \mathrm{C} / \mathrm{min}$ and
Table 1. Properties of the parts in discrete chip

\begin{tabular}{|c|c|c|c|c|}
\hline Parts & $\begin{array}{c}\mathrm{E} \\
(\mathrm{GPa}) \\
\end{array}$ & $\begin{array}{c}\mathrm{CTE} \\
\left(10^{-6} /{ }^{\circ} \mathrm{C}\right) \\
\end{array}$ & $\begin{array}{c}\text { Poisson's } \\
\text { Ratio } \\
\end{array}$ & $\begin{array}{c}\text { Density } \\
\left(\times 10^{-6} \mathrm{~kg} / \mathrm{mm}^{3}\right)\end{array}$ \\
\hline SAC & 43 & 23.2 & 0.3 & 7.370 \\
\hline Si Chip & 130 & 3.5 & 0.22 & 2.33 \\
\hline $\mathrm{Cu}$ baseplate & 129 & 17 & 0.34 & 8.69 \\
\hline $\begin{array}{l}\text { Epoxy Molding } \\
\text { Compounds }\end{array}$ & 17.3 & 30 & 0.35 & 1.78 \\
\hline
\end{tabular}

$-3^{\circ} \mathrm{C} / \mathrm{min}$, respectively. The aging test was stopped after reaching the failure criteria for power semiconductors (junction to case thermal resistance and on-state voltage). While the voltages of new power devices had been $1.51 \mathrm{~V}$ at the nominal current, their voltages reached to $1.81 \mathrm{~V}$ when they had been aged. Junction-case thermal resistances reached to $1.38^{\circ} \mathrm{C} / \mathrm{W}$ (it was $1.15^{\circ} \mathrm{C} / \mathrm{W}$ as the new devices). This test was performed for several 600V-15A IGBTs from Infineon Company, with the commercial product number of IKP15N60T fabricated based on the trench-gate field-stop technology. Roughly every ten cycles, power semiconductors were put out of programmable chamber and were under the test individually by measuring two parameters, namely junction to case thermal resistance and onstate voltage. This test bench was prepared for estimating thermal resistance of power semiconductors based on TSEP [41].

\section{FEM SIMULATION}

Several FEM simulations were performed in order to explain the basic creep behavior of solder joints under different sever thermal loading (different temperature heating and cooling rates and dwelling temperature based on section IV. B). Materialdependent coefficients of Garofalo-Arrhenius constitutive model are used based on the results of standard creep test described in section IV. A. In addition, resulted steady state strain rates of solder joint in FEM simulation will be used in the creep damage model of power semiconductor.

ABAQUS finite element environment was used to investigate the induced strain in the power semiconductor chip. The meshed geometric model of the assembly is presented in Fig. 4. The mesh of assembly includes 53424 elements and 70128 nodes. Coupled temperature-displacement modeling in the transient mode was performed in ABAQUS finite element analysis package. An 8-node thermally coupled brick and trilinear displacement-temperature namely C3D8T was chosen as the element type in the simulation. Several parts with the different physical and geometrical properties existed in the power semiconductor assembly. Therefore different material and physical properties have to be considered. These properties are listed in Table 1 [8]. Joint zone consists of the SAC solder layer, $\mathrm{Cu}$ baseplate and $\mathrm{Si}$ wafer.

The solder layer in power device tolerates thermal cycling loading during accelerated thermal experiments similar to the conditions provided in real applications. Garofalo-Arrhenius constitutive model presents the deformation behavior of the solder layer (elastic and inelastic properties). Creep behavior of solder layer was modeled by the hyperbolic sine creep equation (1). The constant values were extracted from creep test and are $2.73 * 10^{5}(1 / \mathrm{s}), 0.023(\mathrm{MPa})^{-1}, 6.3$ and 6480.3 for $C_{1}, C_{2}, C_{3}$ and $C_{4}$, respectively.

One of the most important failure mechanisms for SAC solders during thermal cycling is the creep phenomenon. Thus, 
creep induced deformation can affect the lifetime of solder layer and propagate the cracks and the voids. Creep strain rate can be extracted using FEM simulation. The average values of creep strain rate in a solder joint was used to estimate the cumulative creep damage process.

\section{RESULTS AND DISCUSSION}

In this section, in order to describe the evolution of creepfatigue event in the solder joint under thermal loading, some basic FEM results are explained in details. In addition, the damage evolution of thermal loading on the solder joint is also explained based on the experimental tests to demonstrate the actual effects of creep-fatigue damage in solder joints.

\section{A. FEM simulation}

Fig. 5 gives the evolution of accumulated creep strain as a function of thermal cycle numbers in different temperature cycle loads. The plot indicates that the increase in number of cycles leads to a growing trend in accumulated creep strain of solder joint. It is also revealed that creep strain rate for every thermal cycle decreases by a temperature decrease in the thermal cycles. Von-Mises stress as a function of time (number of thermal cycle) is depicted in Fig. 6 (a few last cycles). There are 5 different phases in this plot which individually demonstrate a physical behavior occurring in the material. The phases 1 and 2 happen in the heating ramp from $-40{ }^{\circ} \mathrm{C}$ to $170^{\circ} \mathrm{C}$. At these phases, stress relaxation is dominant but much slower at the phase 2 . The effects of staying in the hot dwelling time shows itself as a relaxed stress due to the high temperature exposure and the generation of creep strain (phase 3 ). In the cooling down phase (phase 4) the solder layer tolerates an enormous stress shock intensifying the failure. The reason is the considerable difference in the CTE of the solder layer, chip and the baseplate making a residual stress in the materials. The solder experiences another relaxing stress in the cold dwelling time (phase 5).

\section{B. Thermal cycling test results}

For 3D analysis of microstructure, X-ray Tomography (Tomograph EASYTOMXL (CMTC) with Camera Princeton and X-ray tube Hamamatsu L10711) was employed. Since SAC solder has a very high absorption, very small samples had to be

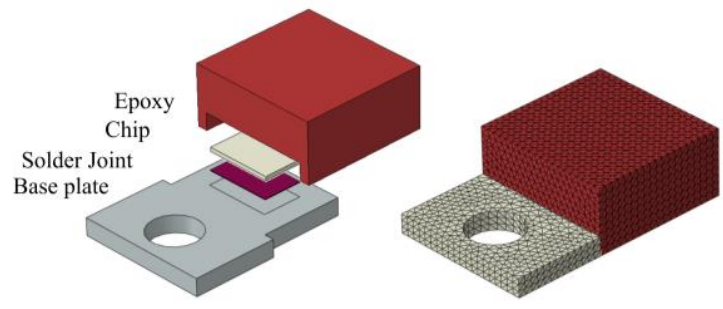

(a)

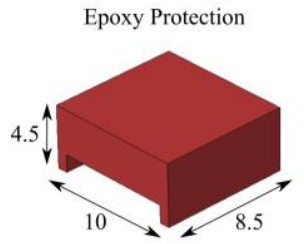

(b)

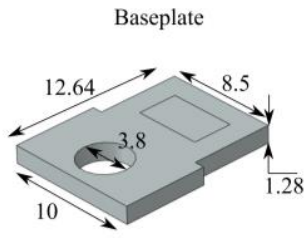

(c)

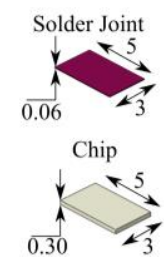$$
30
$$

Fig. 4. Discrete Power semiconductor, a) structure, b) meshed model and c) dimensions in $\mathrm{mm}$. prepared for 3D X-ray Tomography. The samples had been softly polished till they reached to $20 \mu \mathrm{m}$. It is worth-mentioning that the three samples were prepared from the center of solder layers in each assembly.

Fig. 7 illustrates the evolution of a part of solder layer in the power semiconductor as a function of thermal cycle numbers. As given in the tomography images, the increase in volume of voids and their coalescence with the rise in number of thermal cycles is apparent. In general, the damage initiation in a creepfatigue event appears with the nucleation of voids in the solder material. The void nucleation is principally induced by the vacancy accumulation which is the indicator of creep initiation [45]. With the increase in number of thermal cycles, the accumulated strain energy comes into play and leads to the growth of micro-voids adjacent to the intermetallics or secondary phases in the solder joint. The enhanced temperature at the hot dwell time along with the sharp stress changes during the temperature ramps intensify the microstructure instability and act as driving force to merge micro-voids and form cavities in the solder layer. This event leads to advent of failure in the solder joint, as illustrated in Fig. 7e. It is also suggested that the void coalescence phenomenon, as a sign of damage initiation, is intensified in the solder when the strain domain is getting extended around the primary voids with the increase in number of thermal cycles.

Fig. 8 shows the statistical analysis of voids percentage in the solder joints as a function of thermal cycle numbers. The measurements were obtained from the analysis of X-ray tomography. As observed, the percentage of void volume meaningfully increases with the rise in number of thermal cycles. This increment is consistent with the evolution of accumulated creep strain during the thermal cycling. Hence, the combination of results from FEM simulation and experimental work suggests that the accumulated creep strain during cycling is the key factor for damage initiation in the solder joint. It

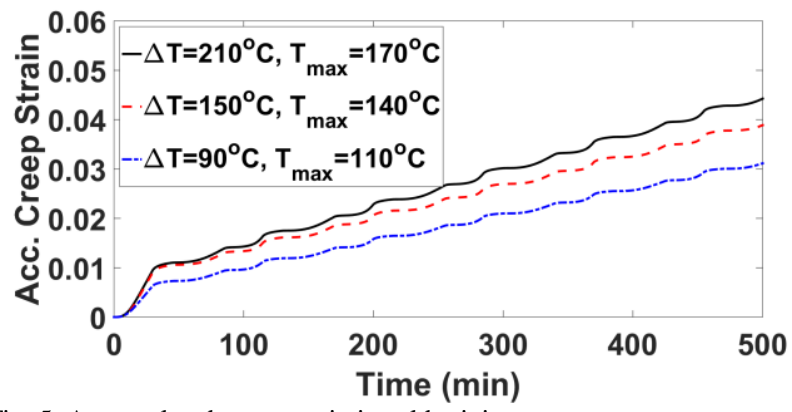

Fig. 5. Accumulated creep strain in solder joint.

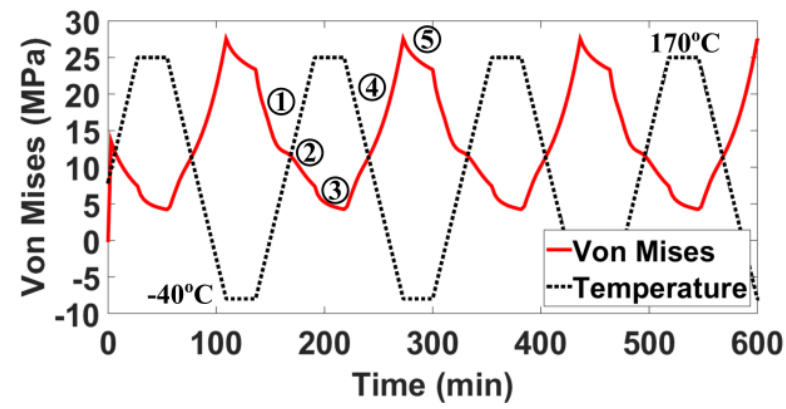

Fig. 6. Von-Mises stress in solder joint. 


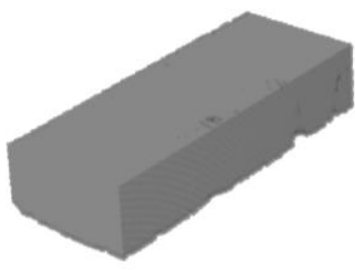

(a)

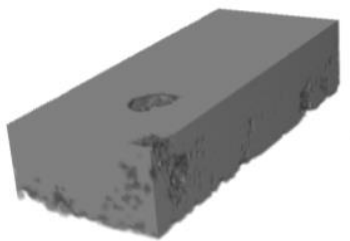

(b)

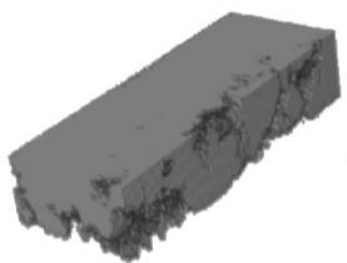

(c)

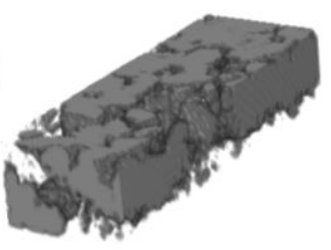

(d)

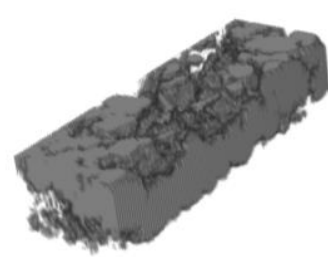

(e)

Fig. 7. 3D X-ray tomography (a) new device, (b) aged device after 600, (c) aged device after 1200, (d) aged device after 1800, (e) aged device after 2500 thermal cycles.

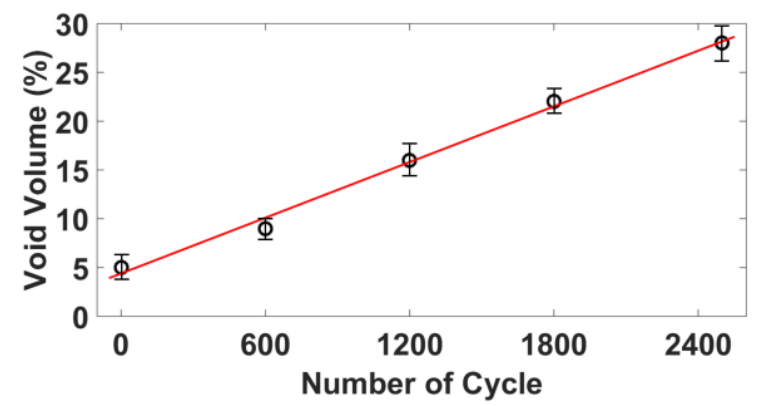

Fig. 8. Void volume versus thermal cycle number.

should be noted that the mechanism of damage is not restricted to the mentioned descriptions and other parameters such as type of void interaction, primary void arrangement and metallurgical phase segregation in the solder material can entangle the reliability assessment and failure behavior of solder joint.

As previously mentioned, die attach degradation is illustrated by crack growth and void coalescence in the solder joint. Elasto-visco-plastic and creep strains in the solder joint owing to the creep failure mechanism is one the main factors in the die attach deterioration. The average deterioration trends of thermal resistance and on-state voltage drop in the power semiconductors is shown in Fig. 9. This figure demonstrates the deterioration trends of thermal resistance and on state voltage drop of the discrete power semiconductors in terms of thermal cycles. These results show a logarithmic trend expressing accelerated aging of power semiconductors.

\section{Power cycling test results}

Several power cycling tests were performed in order to characterize the behavior and to extract the lifetime model of fatigue failure mechanism. The constant coefficients of the lifetime models have been extracted from active power cycling test as following; $\alpha=-4.8, A=750, Q=8.4948 \times 10^{4}$. Fig. 10 also demonstrates the number of cycles to failure as a function of junction temperature swing $\left(\Delta T_{j}\right)$ and mean junction temperature $\left(T_{\text {mean }}\right)$. One can observed that the damage process of the considered power semiconductor increases while either junction temperature swing or mean junction temperature increases. These data have been employed in the fatigue failure lifetime model which was described in (2).

D. Application of the proposed creep-fatigue reliability framework in a power electronic converter employed in a hybrid electric vehicle

The procedure of useful lifetime estimation of power devices exposing to sever thermal cycles was thoroughly discussed in

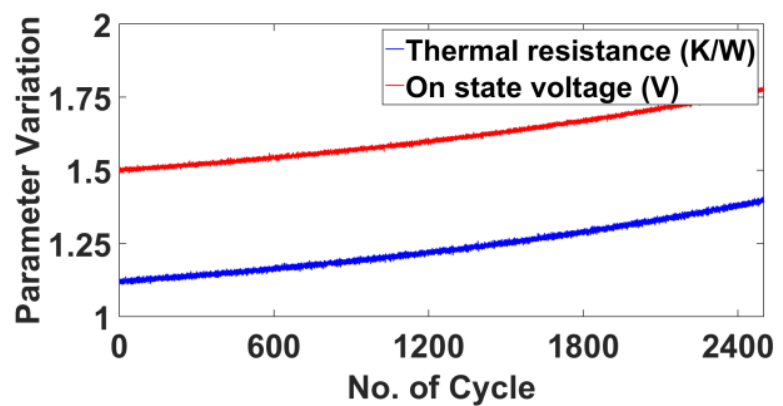

Fig. 9. Parameters drifting during aging.

section III considering both creep and fatigue failure phenomena as the most dominant failure mechanisms.

In this section a real case application would be taken into account to illustrate the effects of creep failure mechanism on the useful lifetime of power devices.

In this case, power devices are assumed to be exposed to the thermal swings caused by worldwide harmonized light-duty vehicles test cycles (WLTC) as shown in Fig. 11. Since the Coffin-Manson-Arrhenius fatigue and Monkman-Grant creep lifetime models are based on the mean temperature and temperature swings and resting time and its corresponding maximum temperature, a special purpose Rainflow algorithm has to be utilized. This special purpose Rainflow algorithm was designed by the authors and reported in [35]. This algorithm is capable of sorting data according to the Coffin-MansonArrhenius fatigue and Monkman-Grant creep lifetime models. Expressing its features is beyond this study and thereby interested readers are referred to [35].

The sorted data is shown in Fig. 12. Number of cycles occurring during one mission profile (Fig. 11) for the fatigue failure mechanism based on Coffin-Manson-Arrhenius lifetime model including mean junction temperature and junction temperature swing is shown in Fig. 12a, while for creep failure mechanism based on Monkman-Grant lifetime model including maximum junction temperature and its corresponding resting time is shown in Fig. 12b. For all the creep cycles, resting time range has been extracted $1 \mathrm{sec}$.

One can obtain useful lifetime of power semiconductors based on the lifetime models and global linear damage model expressing the interaction between creep and fatigue damages. Based on (2), (3) and (7) and the applied mission profile (see Fig. 2), useful lifetime is expected to 66700 hours. While, it is expected over 90000 hours for only considering fatigue failure mechanism based on (2) and (4) and the sorted data (Fig. 12a). This is the case for the previous studies in which creep failure mechanism has been neglected. One can find that there is more 


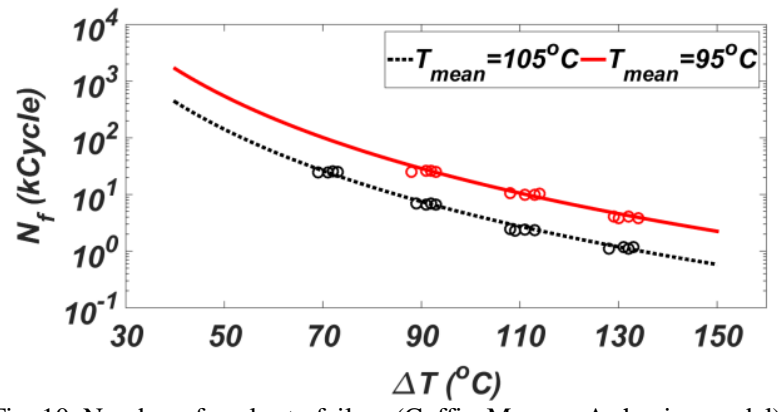

Fig. 10. Number of cycles to failure (Coffin-Manson-Arrhenius model).

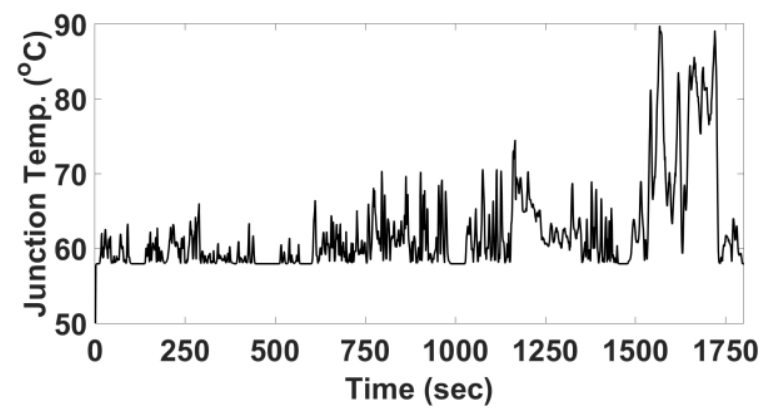

Fig. 11. Power semiconductor junction temperature.

than 23000 hour (34\%) difference in the lifetime estimation by ignoring creep failure mechanism. It means that creep failure mechanism has been activated as a potential failure mechanism in the solder joint regarding its high working temperature. In addition to the high temperature working, since steady state creep strain rate is considerably high due to high junction temperature swing (1), creep damage is also significant based on (6). Accordingly, consideration of creep failure mechanism in the electro thermal reliability of power semiconductor has paramount of importance.

\section{CONCLUSION}

This work aims to obtain the creep effects on the thermomechanical lifetime of solder joint in the power semiconductor in a real application under actual complicated thermal loading. FEM simulations were provided to demonstrate the creep effects on the material behavior. The X-ray tomography, carried

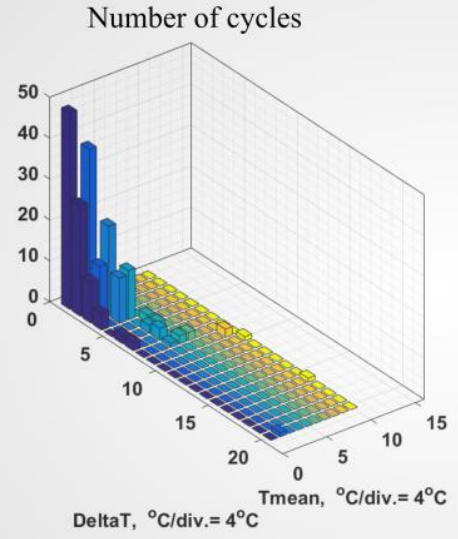

(a)

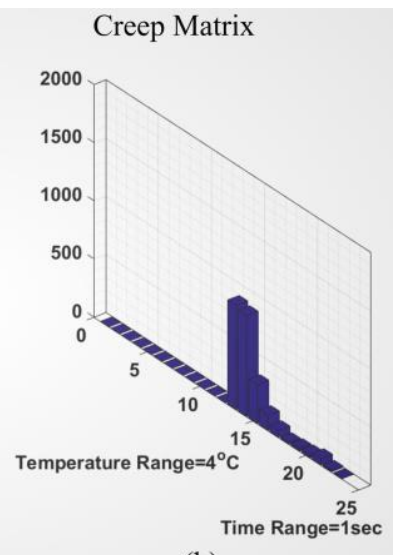

(b)
Fig. 12. Sorted data for (a) Coffin-Manson-Arrhenius fatigue and (b) Monkman-Grant creep lifetime models out on new and aged devices, indicates that void growth and coalescence, as a sign of creep-fatigue process, are occurred in the solder with application of thermal cycles. This event is accompanied with substantial changes in the thermal resistance and on state voltage drop during the damage evolution. Consideration of creep and fatigue failure mechanisms interaction on thermo-mechanical reliability of power devices was thoroughly discussed in this paper. The estimations show that the consideration of creep on fatigue process strongly affects the life prediction of power semiconductors compared to a situation including sole fatigue event.

\section{REFERENCES}

[1] D. Zhou, H. Wang, and F. Blaabjerg, "Mission Profile Based SystemLevel Reliability Analysis of DC/DC Converters for a Backup Power Application," IEEE Trans. Power Electron., vol. 33, no. 9, pp. 80308039, 2018.

[2] S. Yang, A. Bryant, P. Mawby, D. Xiang, L. Ran, and P. Tavner, “An Industry-Based Survey of Reliability in Power Electronic Converters," IEEE Trans. Ind. Appl., vol. 47, no. 3, pp. 1441-1451, 2011

[3] B. Wang, J. Cai, X. Du, and L. Zhou, "Review of power semiconductor device reliability for power converters," CPSS Trans. Power Electron. Appl., vol. 2, no. 2, pp. 101-117, 2017.

[4] H. Wang, M. Liserre, and F. Blaabjerg, "Toward reliable power electronics: Challenges, design tools, and opportunities," IEEE Ind. Electron. Mag., vol. 7, no. 2, pp. 17-26, 2013.

[5] M. K. Alam and F. H. Khan, "Reliability analysis and performance degradation of a boost converter," IEEE Trans. Ind. Appl., vol. 50, no. 6, pp. 3986-3994, 2014.

[6] E. H. Amalu, N. N. Ekere, M. T. Zarmai, and G. Takyi, "Optimisation of thermo-fatigue reliability of solder joints in surface mount resistor assembly using Taguchi method," Finite Elem. Anal. Des., vol. 107, pp. 13-27, Dec. 2015.

[7] B. Talebanpour, U. Sahaym, and I. Dutta, "Effect of Composition and Thermal-Mechanical History on the Creep Behavior of Sn-Ag-Cu Solders-Part II: Model," IEEE Trans. Device Mater. Reliab., vol. 16, no. 3, pp. 326-335, 2016.

[8] V. N. Le, L. Benabou, V. Etgens, and Q. B. Tao, "Finite element analysis of the effect of process-induced voids on the fatigue lifetime of a lead-free solder joint under thermal cycling," Microelectron. Reliab., vol. 65, no. Supplement C, pp. 243-254, 2016.

[9] P. Xu, M. Rauer, M. Kaloudis, and J. Franke, "Simulation-aided analysis of the influence of voids on the reliability of solder-joints for LED-applications," in 2016 6th Electronic System-Integration Technology Conference (ESTC), 2016, pp. 1-5.

[10] K. C. Otiaba, M. I. Okereke, and R. S. Bhatti, "Numerical assessment of the effect of void morphology on thermo-mechanical performance of solder thermal interface material," Appl. Therm. Eng., vol. 64, no. 1, pp. 51-63, 2014.

[11] L. Zhang, L. Sun, Y. Guo, and C. He, "Reliability of lead-free solder joints in CSP device under thermal cycling," J. Mater. Sci. Mater. Electron., vol. 25, no. 3, pp. 1209-1213, Mar. 2014.

[12] Y. Chen, Y. Jin, and R. Kang, "Coupling damage and reliability modeling for creep and fatigue of solder joint," Microelectron. Reliab., vol. 75, pp. 233-238, 2017.

[13] Z.-H. Zhang, X.-S. Wang, H.-H. Ren, S. Jia, and H.-H. Yang, "Simulation study on thermo-fatigue failure behavior of solder joints in package-on-package structure," Microelectron. Reliab., vol. 75, pp. 127-134, Aug. 2017.

[14] L. Zhang, L. Sun, S. Zhong, J. Ma, and L. Bao, "Reliability of Pbfree solder joints in FCBGA using finite element simulation and Taguchi method," in 2015 16th International Conference on Electronic Packaging Technology (ICEPT), 2015, pp. 197-200.

[15] F. Baber and I. Guven, "Solder joint fatigue life prediction using peridynamic approach," Microelectron. Reliab., vol. 79, pp. 20-31, 2017.

[16] B. Metais et al., "A viscoplastic-fatigue-creep damage model for tinbased solder alloy," 2015 16th Int. Conf. Therm. Mech. Multi-Physics Simul. Exp. Microelectron. Microsystems, EuroSimE 2015, pp. 1-5, 
2015.

[17] J. Lemaitre and R. Desmorat, Engineering damage mechanics: ductile, creep, fatigue and brittle failures. Springer Science \& Business Media, 2005.

[18] J. H. L. Pang, B. S. Xiong, and T. H. Low, "Creep and fatigue characterization of lead free $95.5 \mathrm{Sn}-3.8 \mathrm{Ag}-0.7 \mathrm{Cu}$ solder," in 2004 Proceedings. 54th Electronic Components and Technology Conference (IEEE Cat. No.04CH37546), 2004, vol. 2, p. 1333-1337 Vol.2.

[19] K. Zeng and K. N. Tu, "Six cases of reliability study of Pb-free solder joints in electronic packaging technology," Mater. Sci. Eng. R Reports, vol. 38, no. 2, pp. 55-105, 2002.

[20] M. Brincker, S. Söhl, R. Eisele, and V. N. Popok, "Strength and reliability of low temperature transient liquid phase bonded $\mathrm{CuSnCu}$ interconnects," Microelectron. Reliab., vol. 76-77, pp. 378-382, 2017.

[21] J. Wang, X. Long, and Y. Yao, "Effects of aging temperature on tensile and fatigue behavior of $\mathrm{Sn}-3.0 \mathrm{Ag}-0.5 \mathrm{Cu}$ solder joints," $J$. Mater. Sci. Mater. Electron., vol. 28, no. 19, pp. 14884-14892, 2017.

[22] V. Ramachandran and K. Chiang, "Feasibility Evaluation of Creep Model for Failure Assessment of Solder Joint Reliability of WaferLevel Packaging," IEEE Trans. Device Mater. Reliab., vol. 17, no. 4, pp. 672-677, 2017.

[23] E. H. Amalu and N. N. Ekere, "Modelling evaluation of GarofaloArrhenius creep relation for lead-free solder joints in surface mount electronic component assemblies," J. Manuf. Syst., vol. 39, pp. 9-23, Apr. 2016.

[24] A. Syed, "Accumulated creep strain and energy density based thermal fatigue life prediction models for $\mathrm{SnAgCu}$ solder joints," in 2004 Proceedings. 54th Electronic Components and Technology Conference (IEEE Cat. No.04CH37546), 2004, vol. 1, p. 737-746 Vol.1.

[25] M. T. Zarmai, N. N. Ekere, C. F. Oduoza, and E. H. Amalu, "Evaluation of thermo-mechanical damage and fatigue life of solar cell solder interconnections," Robot. Comput. Integr. Manuf., vol. 47, pp. 37-43, Oct. 2017.

[26] W. Lai, M. Chen, L. Ran, O. Alatise, S. Xu, and P. Mawby, "Low\$Delta T_\{j\}\$Stress Cycle Effect in IGBT Power Module DieAttach Lifetime Modeling," IEEE Trans. Power Electron., vol. 31, no. 9, pp. 6575-6585, 2016.

[27] M. Held, P. Jacob, G. Nicoletti, P. Scacco, and M.-. Poech, "Fast power cycling test of IGBT modules in traction application," in Proceedings of Second International Conference on Power Electronics and Drive Systems, 1997, vol. 1, pp. 425-430 vol.1.

[28] R. Bayerer, T. Herrmann, T. Licht, J. Lutz, and M. Feller, "Model for power cycling lifetime of IGBT modules - various factors influencing lifetime," 5th Int. Conf. Integr. Power Syst., pp. 1-6, 2008.

[29] E. H. Amalu and N. N. Ekere, "High temperature reliability of leadfree solder joints in a flip chip assembly," J. Mater. Process. Technol., vol. 212, no. 2, pp. 471-483, 2012.

[30] S. Dusmez, S. H. Ali, M. Heydarzadeh, A. S. Kamath, H. Duran, and B. Akin, "Aging precursor identification and lifetime estimation for thermally aged discrete package silicon power switches," IEEE Trans. Ind. Appl., vol. 53, no. 1, pp. 251-260, 2017.

[31] X. H. Yang, W. X. Yao, and C. M. Duan, "The development of deterministic fatigue cumulative damage theory," Eng. Sci., vol. 15, no. 14 , pp. $81-87,2003$.

[32] E. W. C. Wilkins, "Cumulative damage in fatigue," in Colloquium on Fatigue/Colloque de Fatigue/Kolloquium über Ermüdungsfestigkeit, 1956, pp. 321-332.

[33] S. P. Zhu, H. Z. Huang, L. P. He, Y. Liu, and Z. Wang, "A generalized energy-based fatigue-creep damage parameter for life prediction of turbine disk alloys," Eng. Fract. Mech., vol. 90, pp. 89-100, 2012.

[34] Z. Lv, H.-Z. Huang, S.-P. Zhu, H. Gao, and F. Zuo, "A modified nonlinear fatigue damage accumulation model," Int. J. Damage Mech., vol. 24, no. 2, pp. 168-181, Mar. 2015.

[35] V. Samavatian, H. Iman-eini, and Y. Avenas, "Anefficient online time-temperature-dependent creep-fatigue rain flow counting algorithm," vol. 116, no. April, pp. 284-292, 2018.

[36] G. R. Halford, M. H. Hirschberg, and S. S. Manson, "Creep fatigue analysis by strain-range partitioning," 1971.

[37] E. G. Ellison and A. Al-Zamily, "fracture and life prediction under thermal-mechanical strain cycling," Fatigue Fract. Eng. Mater. Struct., vol. 17, no. 1, pp. 53-67, 1994.

[38] ISO204, "Metallic materials -- Uniaxial creep testing in tension --
Method of test." 2018.

[39] ASTME13900, "Standard Test Methods for Conducting Creep, Creep-Rupture, and Stress-Rupture Tests of Metallic Materials." 2000.

[40] J. H. L. Pang, B. S. Xiong, C. C. Neo, X. R. Mang, and T. H. Low, "Bulk solder and solder joint properties for lead free 95.5Sn-3.8Ag0.7Cu solder alloy," in 53rd Electronic Components and Technology Conference, 2003. Proceedings., 2003, pp. 673-679.

[41] V. Samavatian, Y. Avenas, and H. Iman-Eini, "Mutual and self-aging effects of power semiconductors on the thermal behaviour of DC-DC boost power converter," Microelectron. Reliab., vol. 88-90, no. May, pp. 493-499, 2018.

[42] V. Samavatian, H. Imaneini, and Y. Avenas, "Reliability Assessment of Multistate Degraded Systems: An Application to Power Electronic Systems," IEEE Trans. Power Electron., p. 1, 2019.

[43] V. Samavatian, H. Iman-Eini, Y. Avenas, and S. Shemehsavar, "Reciprocal and Self-Aging Effects of Power Components on Reliability of DC-DC Boost Converter with Coupled and Decoupled Thermal Structures," IEEE Trans. Components, Packag. Manuf. Technol., p. 1, 2019.

[44] Y. Lai, "Power and Temperature Cycling," Imid 2009, 2009. .

[45] M. E. Kassner and T. A. Hayes, "Creep cavitation in metals," Int. J. Plast., vol. 19, no. 10, pp. 1715-1748, 2003. 